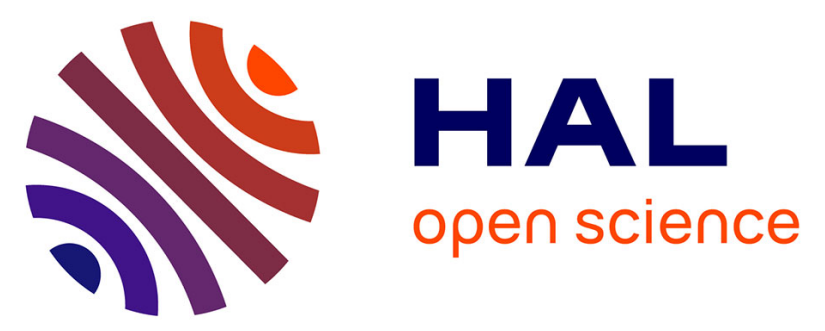

\title{
From the experimental determination of stress-strain full fields during a bulge test thanks to 3D-DIC technique to the characterization of anisotropic Mullins effect
}

\author{
Guilherme Machado, Denis Favier, Grégory Chagnon
}

\section{- To cite this version:}

Guilherme Machado, Denis Favier, Grégory Chagnon. From the experimental determination of stressstrain full fields during a bulge test thanks to 3D-DIC technique to the characterization of anisotropic Mullins effect. 7th European Conference on Constitutive Models for Rubber, Sep 2011, Dublin, Ireland. hal-01978920

\author{
HAL Id: hal-01978920 \\ https://hal.science/hal-01978920
}

Submitted on 11 Jan 2019

HAL is a multi-disciplinary open access archive for the deposit and dissemination of scientific research documents, whether they are published or not. The documents may come from teaching and research institutions in France or abroad, or from public or private research centers.
L'archive ouverte pluridisciplinaire HAL, est destinée au dépôt et à la diffusion de documents scientifiques de niveau recherche, publiés ou non, émanant des établissements d'enseignement et de recherche français ou étrangers, des laboratoires publics ou privés. 


\title{
From the experimental determination of stress-strain full fields during a bulge test thanks to 3D-DIC technique to the characterization of anisotropic Mullins effect.
}

\author{
G. Machado \& D. Favier \& G. Chagnon \\ Laboratoire Sols, Solides, Structures, Risques (3SR) \\ Université de Grenoble/CNRS, Grenoble, France
}

\begin{abstract}
The bulge test is usually mostly used to analyze equibiaxial tensile stress state at the pole of inflated isotropic membranes. Three-dimensional digital image correlation (3D-DIC) technique allows the determination of three-dimensional surface displacements and strain fields. A method is proposed to calculate from these experimental data the membrane curvature tensor at each surface point of the bulge specimen. Curvature tensor fields are then used to investigate axisymmetry of the test; in the axisymmetric case, membrane stress tensor fields are determined from meridional and circumferential curvatures combined with the measurement of the inflating pressure. Stress strain state is then known at any surface point which enriches greatly experimental data deduced from bulge tests. This method is then used to treat an experimental bulge test on a filled silicone rubber membrane. The results highlight that a global membrane with a very heterogeneous strain history is obtained, from equibiaxial behavior at the center of the membrane until a planar (pure) shear state at the periphery of the bulge. Next, different small tensile specimens are cut from the pre-stretched silicone membrane. Identical cyclic tensile tests are realized on all these specimens. The curves are compared and highlight the difference of the stress-softening according to the place of the cut specimen and according to its orientation with respect to the circumferential or meridional direction.
\end{abstract}

\section{INTRODUCTION}

Rubber-like materials exhibit a significant stress softening after a first loading. This phenomenon called Mullins effect has been observed in different paths of deformation during the last six decades. A detailed review for experimental references in different deformations states like uniaxial tension, uniaxial compression, hydrostatic tension, simple shear and equibiaxial tension is given in Diani et al. (2009).

More recently the evidence that stress softening is an inherently anisotropic phenomenon can be found for different rubber-like materials under different load cases. However, these investigations are almost restricted to simple deformation histories. Tension tests performed successively in two orthogonal directions have been the most usual method to point out the strain-induced anisotropy. Results can be seen in Laraba-Abbes et al. (2003) for a carbon-black filled natural rubber as material, Diani et al. (2006) for filled black ethylene propylene diene (EPDM), Itskov et al. (2006) for carbon-black filled acrylate rubber (ACM), Hanson et al. (2005) for a silica-filled polydimethyl- siloxane (PDMS) and Park and Hamed (2000) for different compositions of black filled styrene-butadiene rubber (SBR) and sulfur-cured carbon black filled natural rubber (NR). Simple shear experiments were performed by Muhr et al. (1999), they noticed that strain softening of polysiloxane polymer investigated is smaller in directions orthogonal to the strain cycle causing the softening. Similarly under simple shear, Besdo et al. (2003) showed that a prior loading, generated by a cyclic one-side shear, lead to a material anisotropy verified during a symmetric loading, i.e., both-sided shear. Pawelski (2001) carried out two tests, first, a homogeneous plane-strain compression using a cubic sample of an elastomeric material (VLGQ-rubber) rotated and rotated back by $90^{\circ}$ with respect to the first preloaded configuration. Here a special procedure was required to correct the original measurements since compression is accompanied by friction which spoils the experimental data. Second, for a polyurethane material, a modified biaxial tension with tensile tests on secondary specimens afterward, was used in a way to find an evidence for more complex memory behavior of the material. 
Some models aiming to describe the anisotropy of the stress softening are proposed in the literature (see for example, Diani et al., 2004; Göktepe and Miehe, 2005; Shariff, 2006; Diani et al., 2006; Ehret and Itskov, 2009). All these models provide a solid theoretical basis for mathematical description of the stress softening, like an anisotropic phenomenon, in rubber-like materials. However, the predictive capabilities of models describing the anisotropic Mullins effect are mainly restricted to the uniaxial load case. Horgan et al. (2004) reported that the anisotropic model cannot be validated since suitable experimental data are not available. Pawelski (2001) advised that further experimental works are necessary before one can decide how complex a material constitutive equation for rubber-like material should be. Itskov et al. (2006) pointed out that additional experiments regarding other load cases are needed. This allows to study further the influence of loading cycles with complex deformation states on the appearance and evolution of the Mullins effect in the case of changing principal stretch directions.

Within this context, the aim of this work is to quantify clearly the induced anisotropy according to the applied strain history. The objective is to focus on the strain-induced anisotropy study by verifying the influence of loading cycles in distinct directions using the bulge test to generate different biaxial deformation histories, and cut specimens from the original plate are thus submitted to tensile tests.

\section{EXPERIMENTAL STUDY AND ANALYSIS}

The induced anisotropy by stress softening was experimentally studied. For this purpose, samples were made of a filled silicone rubber called Rhodorsil RTV3428. Supplied as two liquid components, the uncured silicone and the curing agent, this liquid mixture is molded by injection to obtain a sheet with constant thickness Meunier et al. (2008). The final samples are produced by a polyaddition, curing at $70^{\circ} \mathrm{C}$ for $4 \mathrm{~h}$ in order to accelerate the curing process and assure a sufficient cross-linking density. This material exhibits a pronounced stress softening under different load cases, as reported in Machado et al. (2010). In the same work, the manufacture procedure of specimens without any pre-existent anisotropy and testing methods details using three-dimensional image correlation (3D-DIC) are also described. With the 3DDIC technique, it is possible to determine the 3D contour and the in-plane strain fields of the object surface. This process is carried out by correlation of the images, taken by two cameras in the deformed state with their original reference images. The bulge test were used to precondition the samples, i.e., to induce some primary stress-softening. Thus, subsequent uniaxial tensile tests were conducted on preconditioned specimens.

The objective is to propose an experimental test that permits to analyze second tensile load curves in a material that experienced a more complex first load path. A biaxial tensile pre-stretch can be used to generate a complex in-plane deformation history, under incompressibility assumption. The complexity of this deformation history is given by the biaxiality ratio $(\mu)$, that can be expressed as a relation between principal inplane stretches $\left(\lambda_{\max }, \lambda_{\min }\right)$ in the form

$$
\mu=\frac{\ln \left(\lambda_{\min }\right)}{\ln \left(\lambda_{\max }\right)} .
$$

Thus, biaxiality ratio is very useful to characterize the first history imprinted in the material at the first loading. Note that in the uniaxial tensile pre-stretch (Machado et al. (2009)), the contractive stretches are the minimal principal directions, then the biaxiality ratio is fixed in $\mu=-0.5$.

In this work the bulge test is proposed as an original way to yield very different biaxial strain-histories for first load path. As pointed in Machado et al. (2011) bulge test is able to provide more information than the traditional application to determine the material equibiaxial response. It can be used to generate different biaxial states along a radial path of specimen from the equibiaxial state $(\mu=1)$ at the pole until the planar (pure) shear $(\mu=0)$, i.e., a large biaxiality ratio interval $(\mu \in[0,1])$.

Using the 3D-DIC technique, it is possible to determine the three-dimensional surface displacements and the principal stretches $\left(\lambda_{m}, \lambda_{c}\right)$ in the meridional and circumferential directions, as schematized in Fig. 1. From this point forward, these directions will be denoted by the subscripts $m$ and $c$ respectively. Nevertheless, in the axisymmetric case, deformed membrane principal stresses $\left(\sigma_{m}, \sigma_{c}\right)$ are determined from principal curvatures $\left(\kappa_{m}, \kappa_{c}\right)$ combined with the measurement of the inflating pressure $(p)$. These fields are related as follow

$$
\begin{aligned}
\sigma_{m} & =\frac{p}{2 h \kappa_{c}} \\
\sigma_{c} & =\frac{p}{2 h \kappa_{c}}\left(2-\frac{\kappa_{m}}{\kappa_{c}}\right),
\end{aligned}
$$

where $h$ is the current thickness calculated using the incompressibility assumption. $\kappa_{m}$ and $\kappa_{c}$ are deduced from 3D-DIC measurements. Thus, the stress-strain state is then known at any surface point which enriches greatly experimental data deduced from bulge tests. For a comprehensive explanation see Machado et al. (2011).

The specimen geometry consists in thin circular plate, of initial radius $R=90 \mathrm{~mm}$ with a thickness $h_{0}=2 \mathrm{~mm}$. The circular plate is simply supported and subjected to an uniform inflating pressure acting perpendicular to the current configuration. Using the 3D-DIC strain field measures, a set of interest points 


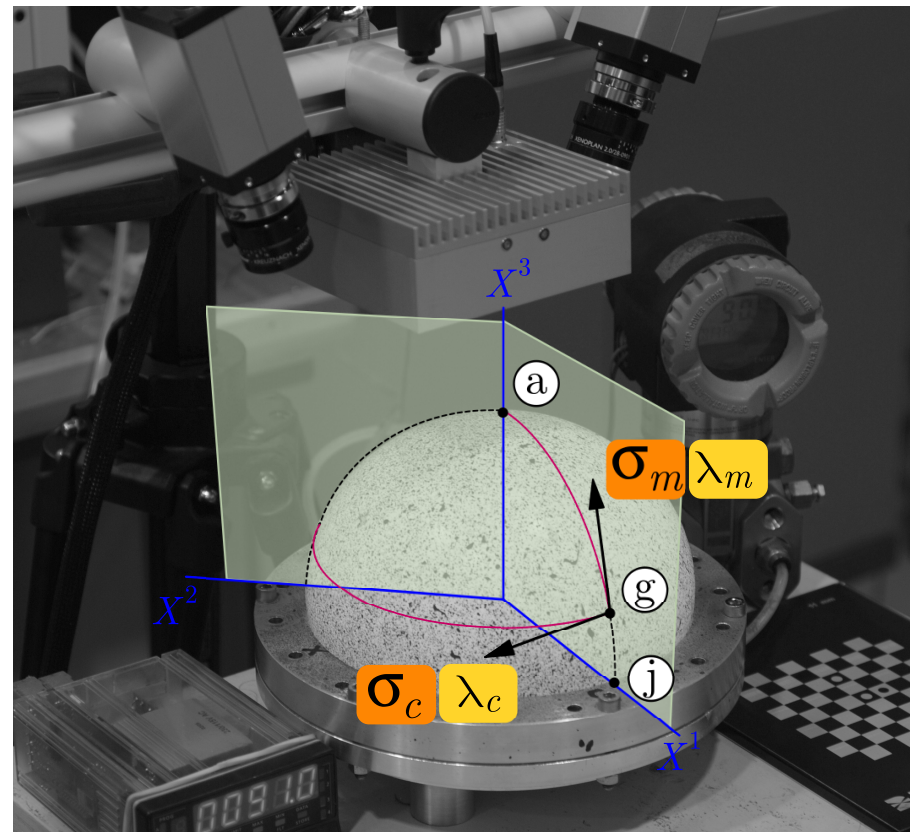

(a)

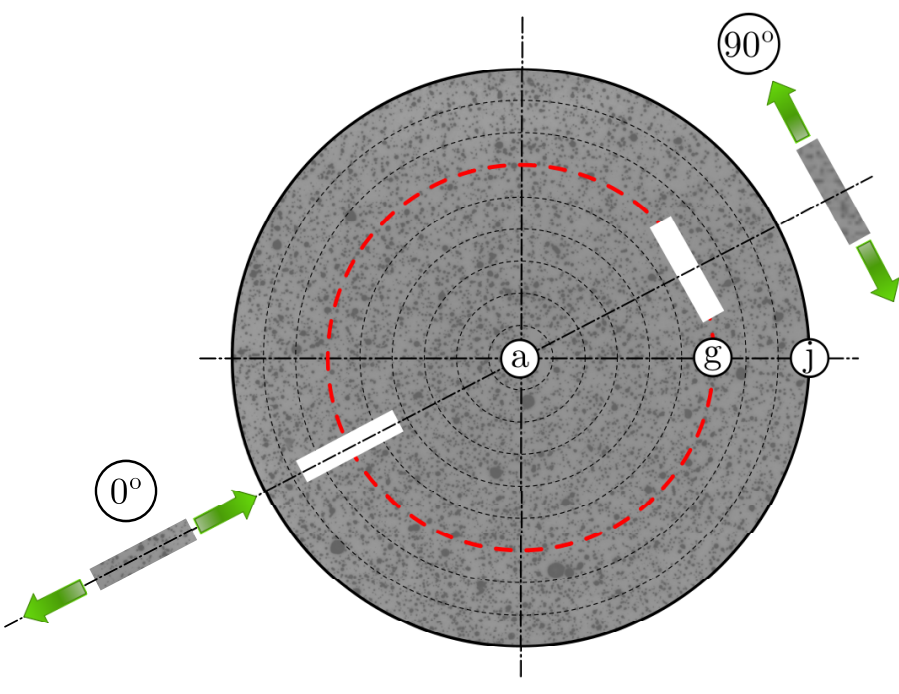

(b)

Figure 1: Schematic representation of biaxial preconditioning method and principal stretches: (a) axisymmetric representation of the bulge test with the interest points; (b) Illustration of the cut subsamples over two different directions in the circular membrane.
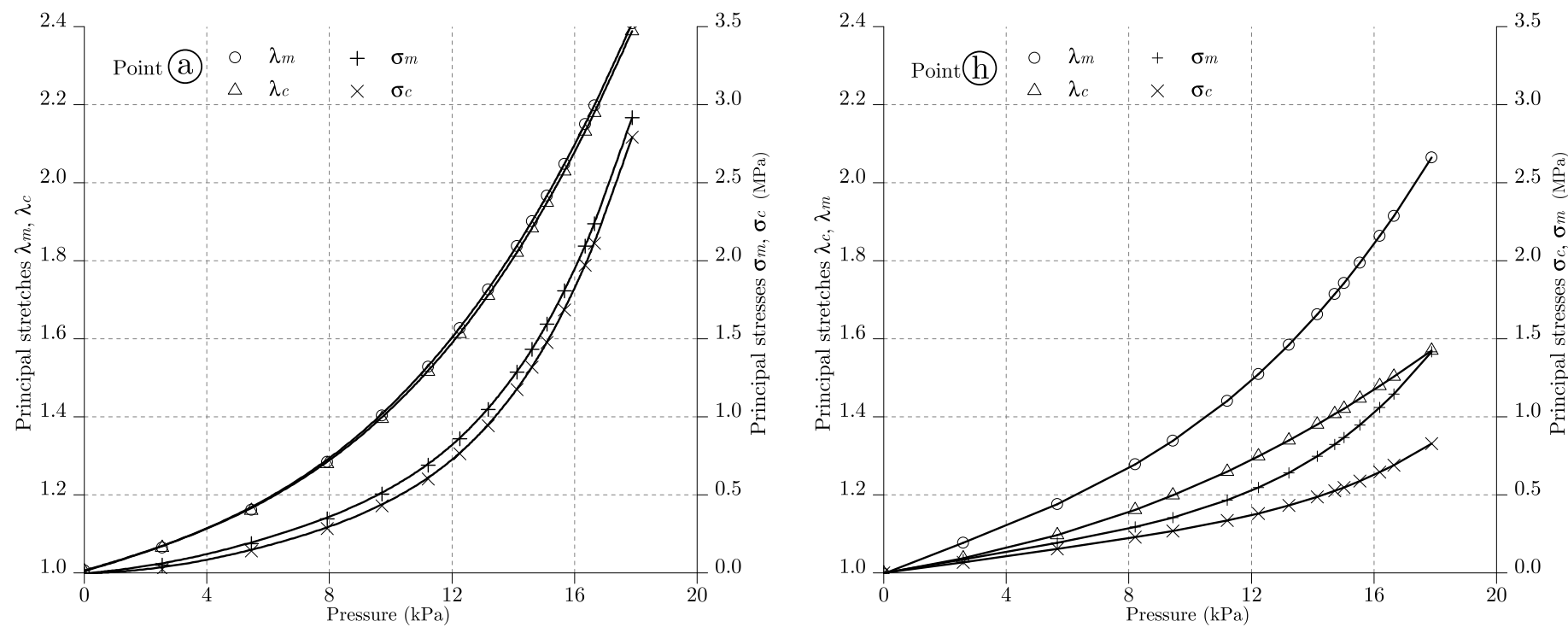

Figure 2: Bulge test deformation history for the points $a$ to $h$. Principal stretches $\left(\lambda_{m}, \lambda_{c}\right)$ and current principal stresses $\left(\sigma_{m}, \sigma_{c}\right)$ are presented respectively on left and right axis according to the inflating pressure $(p)$.

are specified along the radius of undeformed membrane permitting to know the stress and strain histories for every point over the deformed membrane surface. This set of points is represented in the Fig. 1, where each point can be regarded as a small specimen in view of 3D-DIC as a full field strain measure method. Point $a$ corresponds to the membrane center and the other points ( $b$ to $j$ ) are $10 \mathrm{~mm}$ equidistant through the meridional direction.

Fig. 2 presents the first loading strain and stress history of the points $a$ and $h$ in function of the load pressure. Note that each inflation state involves a heterogeneous stress-strain state that evolves from an equibiaxial state at the pole $(R=0 \mathrm{~mm}$ - point $a)$ tending to planar (pure) shear stretching nearest the clamp ( $R=90 \mathrm{~mm}$ - point $j$ ). Machado et al. (2011) pointed out the experimental difficulty concerning the mea- surements on the overall membrane surface and the region near the clamp simultaneously. For materials that experience high displacements a self-shadow effect is observed in this last region.

Fig. 3 presents the mean value and the range of the biaxiality ratio $(\mu)$ for all pressure load steps in each point $a$ to $i$. The measured ratio is almost constant at a given point and variations between the different pressure load steps can be disregarded. Due to the experimental difficulties concerning the measurements near the clamp, the curves in Fig. 3 were extrapolated for the points $i$ and $j$ using polynomial approximation and represented by dotted lines.

After a recovery time of $1 \mathrm{~h}$, a set of tensile test specimens are cut. Two series of samples are defined as follows: samples aligned to the meridional direction denoted by $0^{\circ}$ and samples tangent to the circum- 


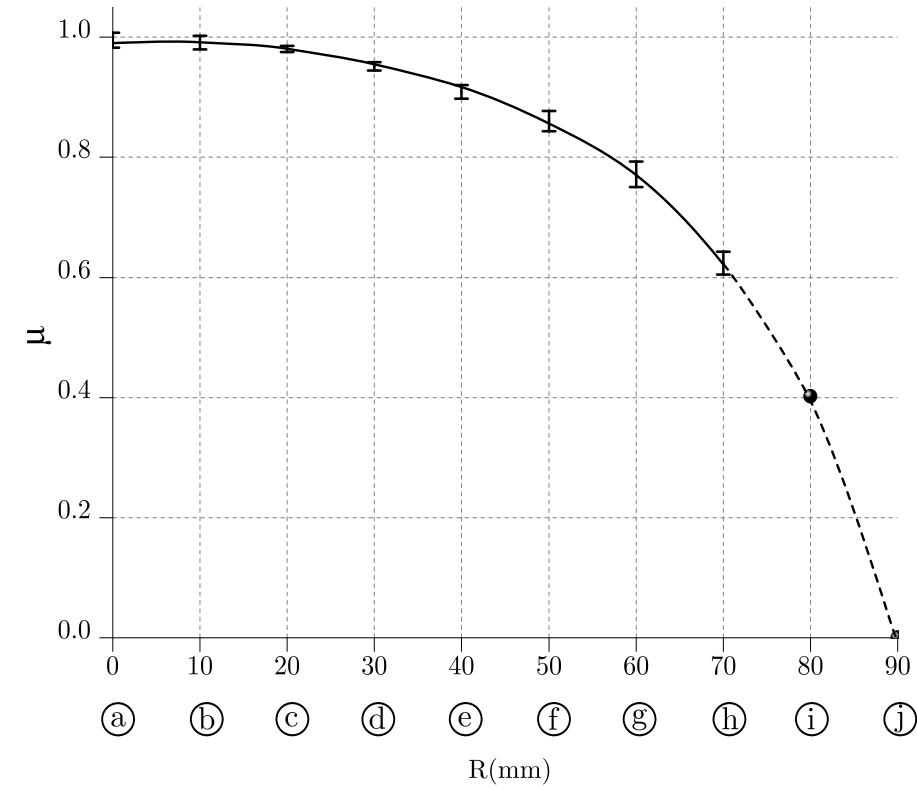

Figure 3: Mean value and range of biaxiality ratio $(\mu)$ during all pressure load steps. Points $i$ and $j$ were extrapolated using a polynomial approximation (dotted lines).

ferential direction (or perpendicular to the meridional direction) denoted by $90^{\circ}$. Both series are illustrated in Fig. 1(b).

At first, the samples aligned to the meridional direction $\left(0^{\circ}\right)$ were submitted to a uniaxial tension test. The loading consists of a simple load unload cycle, where the upper limit overpass the maximum value reached, in the biaxial pre-stretch by the major principal stretch $\left(\lambda_{m}\right)$. Fig. 4 presents the second load curves for the different specimens and a virgin uniaxial tensile load curve (vir) as reference. The load curves of the points $b, c$ and $d$ are quasi superposed, thus they are not represented in the figure keeping clear the results visualization.

It appears that all the curves are different. The figure highlights that closer the sample is from the bulge pole, more stress-softening is observed. Two aspects are observed, the difference between the reference curve (vir) and second load is increasing and the strain-hardening for the return point $(R P)$ on the reference curve appears later. These results are in consistency with the first maximal deformation level presented in Fig. 3(a).

Second, the samples cut at the points perpendicularly to the meridional direction $\left(90^{\circ}\right)$ are tested. However, the second load-unload curves corresponding to points $a$ and $g$ are presented for both directions $\left(0^{\circ}\right.$ and $90^{\circ}$ ) in Fig. 5 and compared to the virgin load curve (vir). The deformation is evaluated locally, using DIC, in a small zone located in the samples center. It clearly appears that the second load curves, for both directions, come back on the first loading curve at that same maximal deformation but with different levels of stress-softening. A stress softening appears in the orthogonal directions as the material was also stretched in this direction during the preconditioning path. This is due to the biaxial pre-loading where the directional intensity of the stress softening depends on the biaxiality ratio $(\mu)$. This emphasizes that subsequent directional behavior is strongly influenced by how the maximal pre-loading is applied.

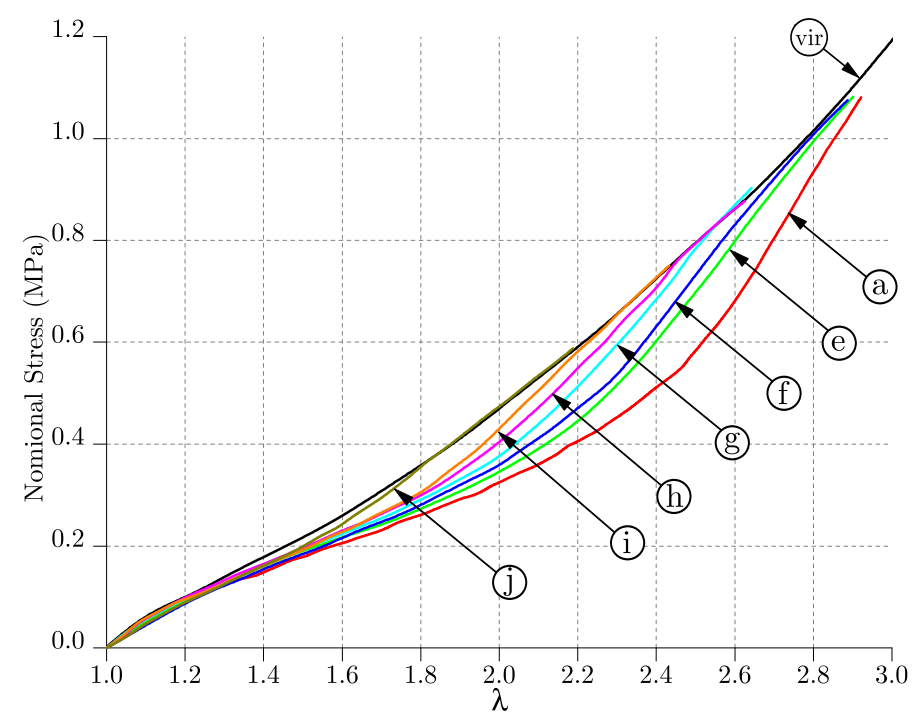

Figure 4: Influence of the biaxial first loading on tensile test response. Uniaxial traction performed at $0^{\circ}$ with respect to the meridional direction for the subsamples a, e, f, g, h, i, and j.

\section{CONCLUSIONS}

The use of bulge test, as a biaxial preconditioning test, was originally proposed to find an evidence for an even more complex memory behavior of the material. The measurements made along the meridian of the inflated membrane provide unprecedented information about the history of principal stress and principal strain directions without an explicit dependency of any constitutive equation. Results showed that the induced anisotropy is dependent on the pre-stretch biaxiality ratio. The return on the first load reference curve of all second load curves occurs at the same point, independently of the second load direction. Note also that the form and intensity of the anisotropy of the Mullins effect could depend on the elastomer type, the properties of filler particles, and their mass and volume proportion in the polymeric matrix.

\section{ACKNOWLEDGE}

We would like to thank the French ANR for supporting this work through the project RAAMO ("Robot Anguille Autonome pour Milieux Opaques")

\section{REFERENCES}

Besdo, D., Ihlemann, J., Kingston, J., and Muhr, A. (2003). Modelling inelastic stress-strain phenomena and a scheme for efficient experimental characterization. In: Busfield, Muhr (eds) Constitutive models for Rubber III. Swets \& Zeitlinger, Lisse., pages 309-317. 

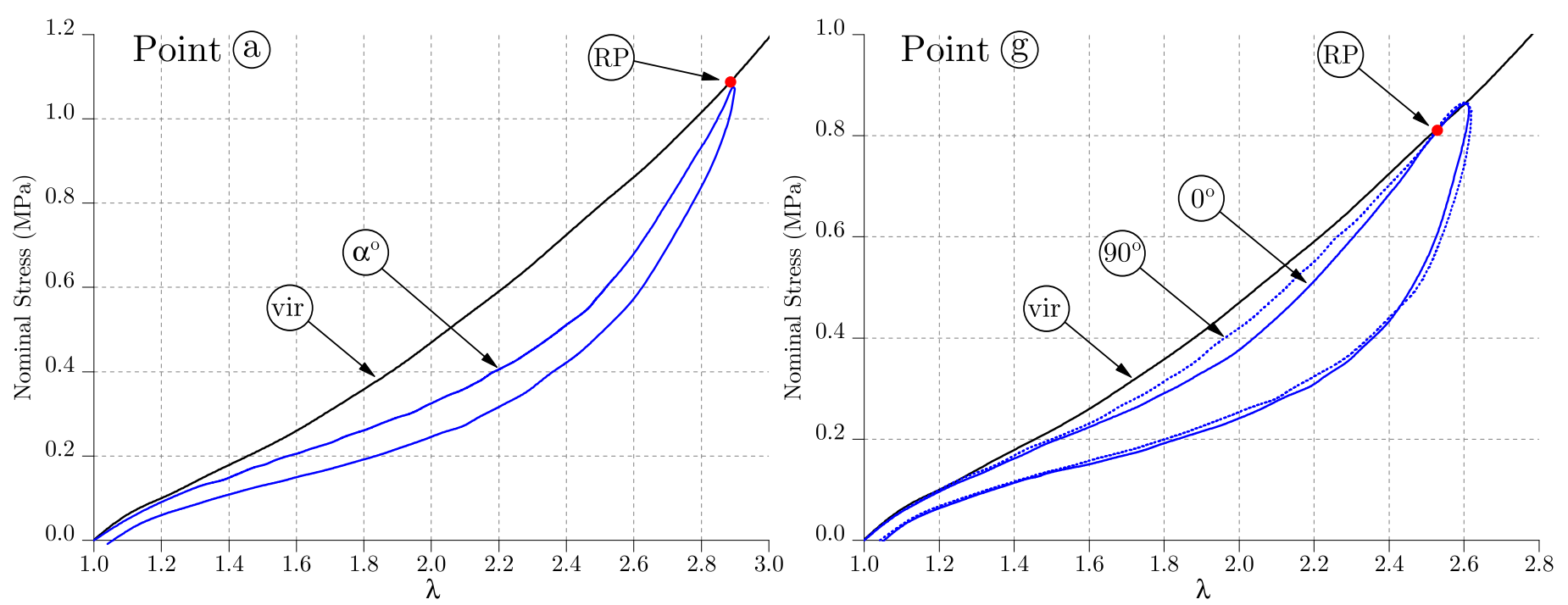

Figure 5: Second load (and unload) curves of specimens $a$ and $g$ cut from the bulge plate at $0^{\circ}$ and $90^{\circ}$ with respect to the meridional direction. Note that, for point $a$, only one curve is presented since the all directions are equivalent.

Diani, J., Brieu, M., Vacherand, J. M., and Rezgui, A. (2004). Directional model isotropic and anisotropic hyperelastic rubber-like materials. Mech. Mater., 36, 313-321.

Diani, J., Brieu, M., and Gilormini, P. (2006). Observation and modeling of the anisotropic viscohyperelastic behavior of a rubberlike material. Int. J. Solids Struct., 43, 3044-3056.

Diani, J., Fayolle, B., and Gilormini, P. (2009). A review on the Mullins effect. Eur. Polym. Journal, 45, 601-612.

Ehret, A. E. and Itskov, M. (2009). Modeling of anisotropic softening phenomena: Aplication to soft biological tissues. Int. J. Plast., 25, 901-919.

Göktepe, S. and Miehe, C. (2005). A micro-macro approach to rubber-like materials. Part III: The microsphere model of anisotropic Mullins-type damage. J. Mech. Phys. Solids, 53, 2259-2283.

Hanson, D. E., Hawley, M., Houlton, R., Chitanvis, K., Rae, P., Orler, E. B., and Wrobleski, D. A. (2005). Stress softening experiments in silica-filled polydimethylsiloxane provide insight into a mechanism for the Mullins effect. Polymer, 46(24), 10989 $-10995$.

Horgan, C. O., Ogden, R. W., and Saccomandi, G. (2004). A theory of stress softening of elastomers based on finite chain extensibility. Proc. R. Soc. London A, 460, 1737-1754.

Itskov, M., Haberstroh, E., Ehret, A. E., and Vohringer, M. C. (2006). Experimental observation of the deformation induced anisotropy of the Mullins effect in rubber. KGK-Kautschuk Gummi Kunststoffe, 59(3), 93-96.
Laraba-Abbes, F., Ienny, P., and Piques, R. (2003). A new tailor-made methodology for the mechanical behaviour analysis of rubber-like materials: II. Application to the hyperelastic behaviour characterization of a carbon-black filled natural rubber vulcanizate. Polymer, 44(3), 821 - 840.

Machado, G., Chagnon, G., and Favier, D. (2009). Experimental observation of induced anisotropy of the mullins effect in particle-reinforced silicone rubber. In Constitutive Models for Rubber VI, pages 511-515-. CRC Press.

Machado, G., Chagnon, G., and Favier, D. (2010). Analysis of the isotropic models of the Mullins effect based on filled silicone rubber experimental results. Mech. Mater., 42(9), $841-851$.

Machado, G., Favier, D., and Chagnon, G. (2011). Membrane curvatures and stress-strain full fields of bulge tests from 3D-DIC measurements. Theory, validation and experimental results on a silicone elastomer. Submitted to Exp. Mech.

Meunier, L., Chagnon, G., Favier, D., Orgéas, L., and Vacher, P. (2008). Mechanical experimental characterisation and numerical modelling of an unfilled silicone rubber. Polym. Test., 27, 765-777.

Muhr, A. H., Gough, J., and Gregory, I. H. (1999). Experimental determination of model for liquid silicone rubber: Hyperelasticity and Mullins effect. In Proceedings of the First European Conference on Constitutive Models forRubber, pages 181-187. Dorfmann A. Muhr A.

Park, B. H. and Hamed, G. R. (2000). Anisotropy in gum and black filled sbr and nr vulcanizates due to large deformation. Korea Polymer Journal, 8, 268275. 
Pawelski, H. (2001). Softening behaviour of elastomeric media after loading in changing directions. Constitutive models for rubber, Besdo, Schuster \& Ihleman (eds), pages 27-34.

Shariff, M. H. B. M. (2006). An anisotropic model of the Mullins effect. J. Eng. Math., 56(4), 415-435. 